\title{
Phylogenetic analysis of the SAP30 family of transcriptional regulators reveals functional divergence in the domain that binds the nuclear matrix
}

\author{
Keijo M Viiri*, Taisto YK Heinonen, Markku Mäki and Olli Lohi
}

Address: Paediatric Research Centre, University of Tampere Medical School and Tampere University Hospital, 33520 Tampere, Finland

Email: Keijo M Viiri* - keijo.viiri@uta.fi; Taisto YK Heinonen - taistoheinonen@gmail.com; Markku Mäki - markku.maki@uta.fi; Olli Lohi - olli.lohi@uta.fi

* Corresponding author

\section{Published: 30 June 2009}

BMC Evolutionary Biology 2009, 9:149 doi:10.1 186/1471-2148-9-149

This article is available from: http://www.biomedcentral.com//47I-2/48/9/149

(c) 2009 Viiri et al; licensee BioMed Central Ltd.

This is an Open Access article distributed under the terms of the Creative Commons Attribution License (http://creativecommons.org/licenses/by/2.0), which permits unrestricted use, distribution, and reproduction in any medium, provided the original work is properly cited.
Received: 20 January 2009

Accepted: 30 June 2009

\begin{abstract}
Background: Deacetylation of histones plays a fundamental role in gene silencing, and this is mediated by a corepressor complex containing $\operatorname{Sin} 3$ as an essential scaffold protein. In this report we examine the evolution of two proteins in this complex, the Sin3-associated proteins SAP3OL and SAP30, by using an archive of protein sequences from 62 species.

Results: Our analysis indicates that in tetrapods SAP30L is more similar than SAP30 to the ancestral protein, and the two copies in this group originated by gene duplication which occurred after the divergence of Actinopterygii and Sarcopterygii about 450 million years ago (Mya). The phylogenetic analysis and biochemical experiments suggest that SAP30 has diverged functionally from the ancestral SAP3OL by accumulating mutations that have caused attenuation of one of the original functions, association with the nuclear matrix. This function is mediated by a nuclear matrix association sequence, which consists of a conserved motif in the C-terminus and the adjacent nucleolar localization signal (NoLS).

Conclusion: These results add further insight into the evolution and function of proteins of the SAP30 family, which share many characteristic with nuclear scaffolding proteins that are intimately involved in regulation of gene expression. Furthermore, SAP30L seems essential to eukaryotic biology, as it is found in animals, plants, fungi, as well as some taxa of unicellular eukaryotes.
\end{abstract}

\section{Background}

The Sin3 multiprotein complex plays a central role in gene silencing by deacetylating histones, and deletion of the mouse SIN3A gene results in lethality at a postimplantation stage of development [1]. SAP30 was initially found in Saccharomyces cerevisiae and human cells as a protein which co-immunopurified with the Sin3 corepressor complex [2-4]. In cultured cells, SAP30 is not necessary for repression activity by the Sin 3 complex, but it participates in N-CoR-mediated repression by specific transcription factors [4]. Thus, it functions as a bridging and stabilizing molecule between the Sin 3 complex and corepressors such as N-CoR [4] and CIR [5], and DNA-binding transcription factors such as YY1 [6]. Mammals have one paralog of SAP30, named "SAP30-like" (SAP30L), which shares $70 \%$ sequence identity with SAP30 [7]. SAP30L also binds to the Sin3A complex and represses transcription when tethered to different promoters [8]. In S. cerevi- 
siae, SAP30 has been shown to be involved in regulation of transcription of the HMR, telomeric, and rDNA loci $[9,10]$, and SAP30-deficient yeast strains have defects in ribosomal rRNA processing [11]. Consistent with a nucleolar function, we have previously identified nucleolar localization signals (NoLSs) in human SAP30 and SAP30L, and showed that they can direct Sin3A to the nucleolus [8].

Recently, we identified by mass spectrometric studies a $\mathrm{C} 2 \mathrm{CH}$-type zinc-binding module in the $\mathrm{N}$-termini of SAP30 and SAP30L [12]. An independent NMR-study also confirmed the results that SAP30 proteins contain $\mathrm{C} 2 \mathrm{CH}-$ type large zinc fingers [13]. This structure is essential for the stability and DNA-binding activity of both proteins. Close to the zinc-binding module resides a polybasic region originally identified as a nuclear localization signal (NLS) in SAP30L [7]. We showed that this region, together with the preceding hydrophobic region, mediates specific interactions of SAP30/SAP30L with the monophosphoinositides (PIPs) PdtIns3P, PtdIns4P and PtdIns5P. Intriguingly, DNA- and PIP-binding occur in the same region and compete with each other. Increasing the concentration of monophosphosphoinositides leads to the release of DNA from SAP30/SAP30L, and reduced transcriptional repression [12]. Furthermore, we showed that SAP30 and SAP30L interact with core histones and nucleosomes and that this interaction is partly mediated by the central acidic region [12].

Nucleotide sequences belonging to the SAP30 family have been found in many eukaryotic species, but most of these putative homologs remain unrecognized and uncharacterized in databases, including those of the NCBI. Here we present a phylogenetic analysis of proteins of the SAP30 family. Our analyses indicate that SAP30L is the ancestral protein of this family and it is found in animals, plants, fungi and some protists. A single duplication event of an ancient SAP30L-bearing chromosome segment gave rise to the SAP30 gene. The most conserved region in SAP30 proteins is in the C-terminus, and we show by biochemical experiments that this region is responsible for association with the nuclear matrix. Phylogenetic analysis reveals that SAP30 has accumulated mutations in its C-terminus, and this has reduced its association with the nuclear matrix. This study suggests that proteins of the SAP30 family play a role in Sin3-mediated repression through multiple interactions with the nuclear matrix, nuclear proteins and DNA.

\section{Results and discussion SAP3O and SAP3OL genes in the human, mouse, chicken and zebrafish genomes}

The human SAP30 and SAP30L genes are located in chromosome bands 4q34.1 and 5q33.2, respectively (Figure
1). Careful analyses reveal that similar genes flank the SAP30 and SAP30L genes in their respective chromosomes and, in fact, these two chromosomes are known to share duplicated segments [14]. The GALNT 10 and GALNT7 genes are located upstream of the SAP30L and SAP30 genes, respectively. On the downstream side, the SAP30L gene is followed by HAND1, and the SAP30 gene by HAND2. It is noteworthy that the degree of sequence identity between the proteins encoded by these flanking genes is similar to that between SAP30 and SAP30L, when aligned by Clustal V. Since the occurrence of a chromosomal duplication event seemed likely, we analyzed other organisms for the presence of this GALNT-SAP-HAND block in order to estimate the time of the duplication event. The mouse and chicken genomes were found to have a similar, conserved GALNT-SAP-HAND organization. The zebrafish has a predicted GALNT gene upstream of the SAP30L gene, and this most likely represents the ancestral chromosome segment because the zebrafish has only one member of the SAP30 family in its genome (see below). In the human genome, the size of the duplicated segment, vectoring the SAP30 family genes between chromosomes 4 and 5, is approximately $400 \mathrm{~kb}$. Comparative analysis of human chromosome 5 [15] has pinpointed this particular $400 \mathrm{~kb}$ region as the interchromosomally duplicated segment. Furthermore, our analysis confirms that this region in chromosome 5 is in fact the donor template for the duplication which gave rise to the SAP30 family 450 Mya, after the Actinopterygii-Sarcopterygii separation [16]. Human chromosome 5 and linkage group 21 (LG21) in the zebrafish have been shown to share most of the conserved syntenies, indicating that these are orthologous chromosomes [17]. Although the genes in these chromosomes were syntenic in the last common ancestor of the zebrafish and human, massive intrachromosomal rearrangements have apparently occurred in the fish and/or mammalian lineages since their divergence. Such rearrangements are known to occur in the SAP30L-harboring human chromosome $5 \mathrm{q}$ region [18], which is frequently deleted in myeloid malignancies such as the $5 \mathrm{q}$ - syndrome. The synteny between the zebrafish LG21 and human chromosome 5 has been disrupted by intrachromosomal translocations and inversions of chromosome segments. The fact that the GALNTSAP microsynteny has been preserved between fish and human chromosomes, and between human chromosomes 4 and 5 , indicates that these genes may have some kind of cooperative function. Perhaps they are under common regulation or even give rise to chimeric transcripts, which are in fact predicted in the USCS database [19].

\section{Identification of members of the SAP30 family and conserved regions in the protein}

A database of sequences judged to be members of the SAP30 protein family was compiled (Table 1 ). Altogether, 

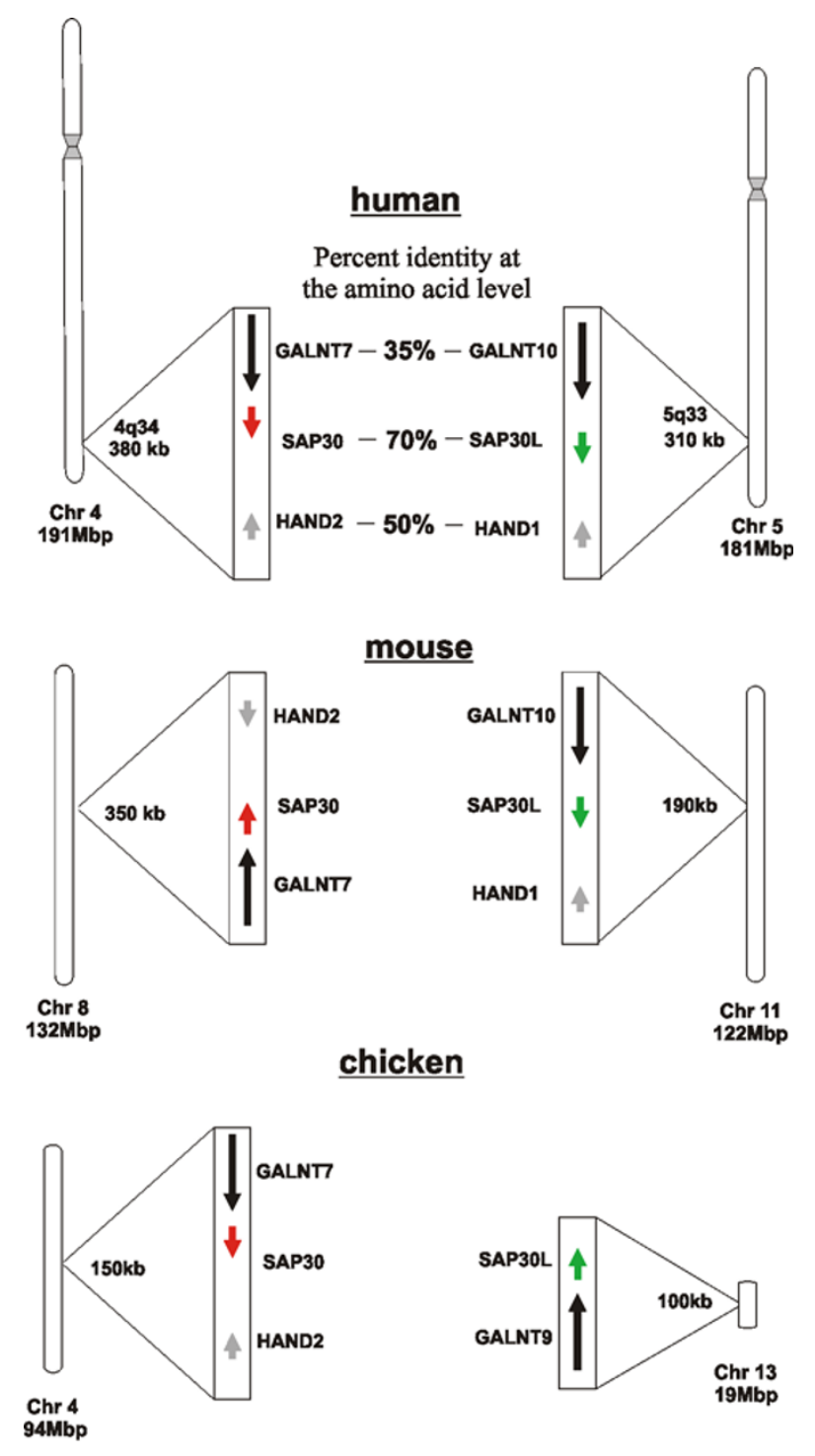

zebrafish

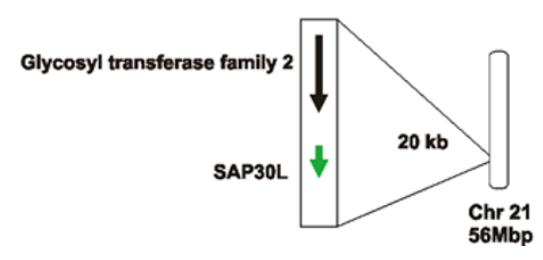

Figure I

Chromosomal localizations of the SAP30 family genes in the Homo sapiens, Mus musculus, Gallus gallus and Danio rerio genomes. The chromosome number and the approximate length (in Mb) are indicated below each chromosome. The lengths of the syntenies are presented in $\mathrm{kb}$. The degree of similarity in the derived amino acid sequence in the Clustal $\mathrm{V}$ alignment is indicated as a percentage of identical residues for the human genes.
62 members of the SAP30 family were identified by PsiBlast searches with the human SAP30L sequence on a non-redundant protein sequence database. SAP30 family sequences were found in a variety of species from Animalia, Plantae and Fungi, as well as in several green algae but not in any chloroplastless protist. In addition, one SAP30 family member in the ambiguous Mycetozoan group was found. In the yeasts, our searches identified SAP30 family members in only two subphyla within the phylum Ascomycota: Saccharomycotina and Pezizomycotina. The third subphylum, Taphrinomycotina seems to have lost SAP30 family proteins during evolution, as we could not find any recognizable sequences from this subphylum, when Schizosaccharomyces pombe, as a representative species whose whole genome has been sequenced, was analyzed (from the NCBI database or the $S$. pombe gene database from Sanger Institute). The composition of the Sin 3 corepressor complex in $S$. pombe seems to be distinct from that in other eukaryotes as its genome is reported to also lack SAP1 8 and SDS3 [20], other core members of the complex. According to a comprehensive analysis of yeast evolution [21], Taphrinomycotina is the earliest diverging clade within the phylum Ascomycota, and this divergence is estimated to have occurred $1140 \pm 80$ Mya [22]. However, SAP30L was also found in plants and the green algae Chlamydomonas reinhardtii (see alignment in additional file 1). Molecular clock analyses indicate that plants separated from the lineage leading to the mycetozoans and fungi about $1580 \pm 90$ Mya [22] and thus, this is also the estimated age of the SAP30 family.

Multiple Clustal W alignment of sequences of the SAP30 family identified a highly conserved region in the C-terminus (Figure 2), which consists mainly of aliphatic (I, L, V), aromatic (F, Y, W, H) and charged $(\mathrm{H}, \mathrm{K}, \mathrm{R}, \mathrm{D}, \mathrm{E})$ residues. Moreover, when the alignment is examined according to the physiochemical properties of the amino acids, this region shows $100 \%$ conservation in the nine C-terminal residues. The consensus sequence of this conserved C-terminal motif is [hydrophobic]-x(2)-[hydrophobic][hydrophobic]-x(4)-[hydrophobic] - $x$-[amphoteric]-x(2)[hydrophobic]-[aliphatic]-x(2)-[hydrophobic]-[hydrophobic].

The Clustal W alignment of SAP30/SAP30L sequences shown in Figure 2 also revealed that the nucleolar localization signal (NoLS) [8], which consists of basic amino acids is quite conserved among the species studied. Although there is no striking co-aligning NoLS in yeast and plants sequences, they contain polybasic region preceding C-terminal motif. As a conclusion, the C-terminal domain, NoLS motif and the Sin3-interacting domain (SID) represent the most ancient region in proteins of the SAP30 family, and this domain evidently appeared early in the evolution of this family. Despite the apparent lack 
Table I: SAP30 family proteins used for amino acid sequence alignment.

\begin{tabular}{|c|c|c|c|c|c|}
\hline Number & Name & Identifier & Organism & Taxonomy & Description \\
\hline 1 & $\mathrm{Hs} 30$ & gi|4506783 & Homo sapiens & Eu., mt., vt., mam. & SAP30 \\
\hline 2 & $\operatorname{Mam} 30$ & gi|| $09076|8|$ & Macaca mulatta & Eu., mt., vt., mam. & PREDICTED: similar to SAP30 isoform 2 \\
\hline 3 & $\mathrm{Pt} 30$ & gi|| I 4596884 & Pan troglodytes & Eu., mt., vt., mam. & PREDICTED: SAP30 isoform 2 \\
\hline 4 & $\mathrm{Bt} 30$ & gi|II 9896054 & Bos taurus & Eu., mt., vt., mam. & PREDICTED: similar to SAP30 \\
\hline 5 & $\operatorname{Mm} 30$ & gi|| 2408290 & Mus musculus & Eu., mt., vt., mam. & SAP30 \\
\hline 6 & $\mathrm{Cf} 30$ & gi|73993665 & Canis familiaris & Eu., mt., vt., mam. & PREDICTED: similar to SAP30 \\
\hline 7 & Оa30 & gi|| 494 I 2039 & Ornithorhynchus anatinus & Eu., mt., vt., mam. & PREDICTED: SAP30 \\
\hline 8 & Md30 & gi| $\mid 2633$ | 237 & Monodelphis domestica & Eu., mt., vt., mam. & PREDICTED: similar to SAP30 \\
\hline 9 & $\mathrm{Gg} 30$ & gi|l| I8090I3। & Gallus gallus & Eu., mt., vt., av. & PREDICTED: similar to SAP30 \\
\hline 10 & $\mathrm{Xt} 30$ & gi|62860074 & Xenopus tropicalis & Eu., mt., vt., amp. & SAP30 \\
\hline 11 & $\mathrm{X} 130$ & gi| | 48227208 & Xenopus laevis & Eu., mt., vt., amp. & MGC99III protein \\
\hline 12 & $\mathrm{Hs} 30 \mathrm{~L}$ & gi|74734226 & Homo sapiens & Eu., mt., vt., mam. & SAP30L, NS4ATP2, FLJII526 \\
\hline 13 & Mam30L & gi|| 09079479 & Macaca mulatta & Eu., mt., vt., mam. & Predicted: similar to SAP30L \\
\hline 14 & $\mathrm{Bt} 30 \mathrm{~L}$ & gi| I I 9923830 & Bos taurus & Eu., mt., vt., mam. & Predicted: hypotethical protein \\
\hline 15 & $\mathrm{Mm} 30 \mathrm{~L}$ & gi| $124487 \mid 93$ & Mus musculus & Eu., mt., vt., mam. & SAP30L \\
\hline 16 & $\mathrm{Rn} 30 \mathrm{~L}$ & gi| 109490760 & Rattus norvegicus & Eu., mt., vt., mam. & PREDICTED: similar to SAP30L \\
\hline 17 & Gg30L & gi|II 8097434 & Gallus gallus & Eu., mt., vt., av. & Predicted: hypotethical protein \\
\hline 18 & $\mathrm{Xt30L}$ & gi|62858467 & Xenopus tropicalis & Eu., mt., vt., amp. & hypothetical protein LOC549895 \\
\hline 19 & $\mathrm{XI30L}$ & gi| 160358663 & Xenopus laevis & Eu., mt., vt., amp. & SAP30L-A \\
\hline 20 & Dr30L & gi|475507II & Danio rerio & Eu., mt., vt., acti. & SAP30L \\
\hline 21 & Tn30L & gi|4722। 378 & Tetraodon nigroviridis & Eu., mt., vt., acti. & unnamed protein product \\
\hline 22 & $\mathrm{Aa} 30 \mathrm{~L}$ & gi| $157 \mid 12936$ & Aedes aegypti & Eu., mt., art., ins. & SAP30 \\
\hline 23 & $\mathrm{Ag} 30 \mathrm{~L}$ & gi| I I 8794370 & Anopheles gambiae str. PEST & Eu., mt., art., ins. & AGAP001654-PA \\
\hline 24 & $\mathrm{Am} 30 \mathrm{~L}$ & gi|6650950I & Apis mellifera & Eu., mt., art., ins. & PREDICTED: similar to CG4756-PA \\
\hline 25 & Dp30L & gi| I 25983642 & Drosophila pseudoobscura & Eu., mt., art., ins. & GAI8408-PA SAP30 \\
\hline 26 & Dm30L & gi||18859859 & Drosophila melanogaster & Eu., mt., art., ins. & CG4756-PA SAP30 \\
\hline 27 & Tc30L & gi|910806 I l & Tribolium castaneum & Eu., mt., art., ins. & PREDICTED: similar to CG4756-PA \\
\hline 28 & $\mathrm{Sp} 30 \mathrm{~L}$ & gi|II561067I & Strongylocentrotus purpuratus & Eu., mt., ech & PREDICTED: similar to Sap30-like \\
\hline
\end{tabular}


Table I: SAP30 family proteins used for amino acid sequence alignment. (Continued)

\begin{tabular}{|c|c|c|c|c|c|}
\hline 29 & Nv30L & gi| 156369622 & Nematostella vectensis & Eu., mt., cnid. & predicted protein \\
\hline 30 & $\mathrm{Dd} 30 \mathrm{~L}$ & gi|66810369 & Dictyostelium discoideum AX4 & Eu., myc. & $\begin{array}{l}\text { hypothetical protein } \\
\text { DDBDRAFT_0185724 }\end{array}$ \\
\hline 31 & Vv30L & gi| 157335386 & Vitis vinifera & Eu., virid., strept. & unnamed protein product \\
\hline 32 & $\mathrm{VP} 30 \mathrm{~L}$ & $\mathrm{gi} \mid 85070180$ & Vitis pseudoreticulata & Eu., virid., strept. & unknown \\
\hline 33 & At30L & gi|| 8394724 & Arabidopsis thaliana & Eu., virid., strept. & unknown protein \\
\hline 34 & At30L-B & gi| | 45327243 & Arabidopsis thaliana & Eu., virid., strept. & unknown protein \\
\hline 35 & Osj30L & gi|7870834l & Oryza sativa (japonica cultivar-group) & Eu., virid., strept. & expressed protein \\
\hline 36 & Osj30L-B & gi| I I 5457076 & Oryza sativa (japonica cultivar-group) & Eu., virid., strept. & Os04g0I 66600 \\
\hline 37 & $\mathrm{Cr} 30 \mathrm{~L}$ & gi| 159464042 & Chlamydomonas reinhardtii & Eu., virid., chlor. & $\begin{array}{l}\text { hypothetical protein } \\
\text { CHLREDRAFT_190150 }\end{array}$ \\
\hline 38 & OI30L & gi|| 45350235 & Ostreococcus lucimarinus CCE990I & Eu., virid., chlor. & predicted protein \\
\hline 39 & Ot30L & gi|II 6059598 & Ostreococcus tauri & Eu., virid., chlor. & unnamed protein product \\
\hline 40 & YI30L & gi|50556448 & Yarrowia lipolytica & Eu., Fungi, sacch. & hypothetical protein \\
\hline 41 & Asg30L & gi|45I 9088I & Ashbya gossypii ATCC 10895 & Eu., Fungi, sacch. & AER278WP \\
\hline 42 & $\mathrm{KI} 30 \mathrm{~L}$ & gi|50308899 & Kluyveromyces lactis & Eu., Fungi, sacch. & unnamed protein product \\
\hline 43 & $\mathrm{Cg} 30 \mathrm{~L}$ & gi|50288935 & Candida glabrata & Eu., Fungi, sacch. & unnamed protein product \\
\hline 44 & Vap30L & gi| 156845457 & Vanderwaltozyma polyspora DSM 70294 & Eu., Fungi, sacch. & hypothetical protein Kpol_54Ip4 \\
\hline 45 & Ps30L & gi| $126 \mid 36507$ & Pichia stipitis CBS 6054 & Eu., Fungi, sacch. & predicted protein \\
\hline 46 & Sc30L & gi|6323919 & Saccharomyces cerevisiae & Eu., Fungi, sacch. & SAP30 \\
\hline 47 & $\mathrm{Dh} 30 \mathrm{~L}$ & gi|50425I6I & Debaryomyces hansenii CBS767 & Eu., Fungi, sacch. & hypothetical protein DEHAOF20284g \\
\hline 48 & $\mathrm{Pg} 30 \mathrm{~L}$ & gi| | 4642 | 845 & Pichia guilliermondii ATCC 6260 & Eu., Fungi, sacch. & hypothetical protein PGUG_00243 \\
\hline 49 & $\mathrm{Ca} 30 \mathrm{~L}$ & gi|68489492 & Candida albicans SC53I4 & Eu., Fungi, sacch. & putative SAP30 \\
\hline 50 & Le30L & gi|| 49237879 & $\begin{array}{l}\text { Lodderomyces elongisporus NRRL YB- } \\
4239\end{array}$ & Eu., Fungi, sacch. & conserved hypothetical protein \\
\hline 51 & $\mathrm{Bf30L}$ & gi| I54298394 & Botryotinia fuckeliana B05.10 & Eu., Fungi, pez. & hypothetical protein BCIG_II652 \\
\hline 52 & $\mathrm{Ci} 30 \mathrm{~L}$ & gi|l। 9178679 & Coccidioides immitis RS & Eu., Fungi, pez. & hypothetical protein CIMG_08I47 \\
\hline 53 & Chg30L & gi|l|16196544 & Chaetomium globosum CBS I48.5I & Eu., Fungi, pez. & hypothetical protein CHGG_04870 \\
\hline 54 & Ac30L & gi| 121715712 & Aspergillus clavatus NRRL I & Eu., Fungi, pez. & conserved hypothetical protein \\
\hline 55 & Af30L & gi|7| 001656 & Aspergillus fumigatus Af293 & Eu., Fungi, pez. & conserved hypothetical protein \\
\hline 56 & An30L & gi|| 45232103 & Aspergillus niger & Eu., Fungi, pez. & hypothetical protein An02g03790 \\
\hline
\end{tabular}


Table I: SAP30 family proteins used for amino acid sequence alignment. (Continued)

\begin{tabular}{cccccl}
\hline 57 & Scc30L & gi|I56045I0I & Sclerotinia sclerotiorum 1980 & Eu., Fungi, pez. & hypothetical protein SSIG_09739 \\
\hline 58 & Nf30L & gi|II I948I227 & Neosartorya fischeri NRRL I8I & Eu., Fungi, pez. & conserved hypothetical protein \\
\hline 59 & Nc30L & gi|85I05620 & Neurospora crassa OR74A & Eu., Fungi, pez. & hypothetical protein \\
\hline 60 & Ao30L & gi|83769778 & Aspergillus oryzae & Eu., Fungi, pez. & unnamed protein product \\
\hline 61 & Asn30L & gi|67540052 & Aspergillus nidulans FGSC A4 & Eu., Fungi, pez. & hypothetical protein AN6I96.2 \\
\hline 62 & Pn30L & gi|I60703739 & Phaeosphaeria nodorum SNI5 & Eu., Fungi, pez. & hypothetical protein SNOG_I2725 \\
\hline
\end{tabular}

Note that the S. cerevisiae SAP30 is judged to be SAP30L (see data presented below) and named as such (Sc30L) for coherence. acti. = Actinopterygii, amp. $=$ Amphibia, art. $=$ Arthropoda, eu. $=$ Eukaryota, ins. $=$ Insecta, invt $=$ Invertebrata, mam. $=$ Mammalia, $\mathrm{mt}=$ Metazoa, $\mathrm{vt}=$ Vertebrata, av. $=$ Aves, ech. $=$ Echinodermata, cnid. $=$ Cnidaria, myc. $=$ Mycetozoa, virid. $=$ Viridiplantae, chlor. $=$ Chlorophyta, strept. $=$ Streptophyta, sacch. $=$ Saccharomycotina, pez. $=$ Pezizomycotina .

of a co-aligning NoLS in yeasts, the reported functions of SAP30 in rDNA transcription $[9,10]$ and ribosome biogenesis [11] suggest that SAP30 is targeted to the nucleolus, and fulfills these functions in yeasts as well.

\section{Conserved domain structure in proteins of the SAP30 family within animals}

The alignment of animal SAP30 and SAP30L sequences revealed several conserved regions in these proteins (Figure 2 and Additional file 2). One of these is the N-terminal zinc-dependent module, in which all four zinccoordinating residues (CCCH) [12] are strictly conserved. The distances between these zinc-coordinating residues are highly conserved as $\mathrm{C}-\times(8)-\mathrm{C}-\times(35)-\mathrm{C}-\times(2)-\mathrm{H}$, suggesting that they are critical for proper folding of the zincbinding module. The amino acids at the DNA-binding interface in the loop region are also well conserved, and show mainly conservative substitutions consisting of polar and basic residues. The DNA/PIP-binding domain [12], which constitutes the NLS motif [7] and comprises the polybasic region adjacent to the zinc-binding module, is also well conserved, as are the NoLS motif, SID domain and the acidic central region that contributes to histone and nucleosome binding $[7,8,12]$. The high degree of conservation indicates that all these modules are probably important for the function of the SAP30 family proteins.

\section{Phylogenetic analysis and timing of the SAP30L gene duplication}

Phylogenetic trees were generated from the Clustal W alignment (Figure 2) of the SAP30 protein sequences presented in Table 1 using the distance, parsimony and likelihood methods. Statistical confidence was measured by Jackknife analysis with 1000 "delete-half jackknife" data sets except in the likelihood method, in which case only 100 data sets were measured due to constraints imposed by computation time. All three methods gave trees with congruent topologies, the main discrepancies being the varying positions of the single representatives from the
Echinodermata, Cnidaria and Mycetozoa. A reliable positioning of these sequences would probably require more data from these taxa, and prefererably from the intermediate taxa as well, but the content of the current databases does not allow this. The extensive sequence divergence observed within the yeasts (Additional file 3) may also explain the non-monophyly of the Ascomycota in the both the parsimony and the likelihood trees. In the distance tree (Figure 3), as well as in the parsimony and likelihood trees (Additional files 4 and 5), SAP30 proteins clearly fall into one group (with Jackknife percentage values of $93.4 \%, 99.8 \%$ and $88 \%$ for the distance, parsimony and likelihood methods, respectively). This strongly supports a single origin for the SAP30 protein family. The presence of SAP3OL and the absence of SAP30 in the fish (Danio rerio and Tetraodon nigroviridis) genomes suggests that the SAP30 gene originated from the ancestral SAP30L gene by duplication of a chromosome segment after the divergence of fishes (Actinopterygii, ray-finned fishes) but before the divergence of amphibians which belong to the Sarcopterygii (lobe-finned fishes). In fact, according to an analysis by Friedman et al. $77.7 \%$ of the interchromosomal duplication events that can be seen in the human genome have occurred prior to the amniote-amphibian separation [14]. Careful inspection of the animal SAP30/ SAP30L sequences (Additional file 2) reveals that many amino acid substitutions are characteristic for either SAP30 or SAP30L (apomorphic), and therefore carry phylogenetic information about the duplication of the SAP30L gene.

\section{Functional divergence of the paralogous SAP30 and SAP30L genes}

It is noteworthy that the tetrapodan SAP30 orthologs from frogs to humans (Sarcopterygii) are much more dispersed in the distance tree than are the SAP30L orthologs in the corresponding species (Figure 4). This is also evident in the alignment of animal SAP30/SAP30L sequences (Additional file 2). The sarcopterygian SAP30 


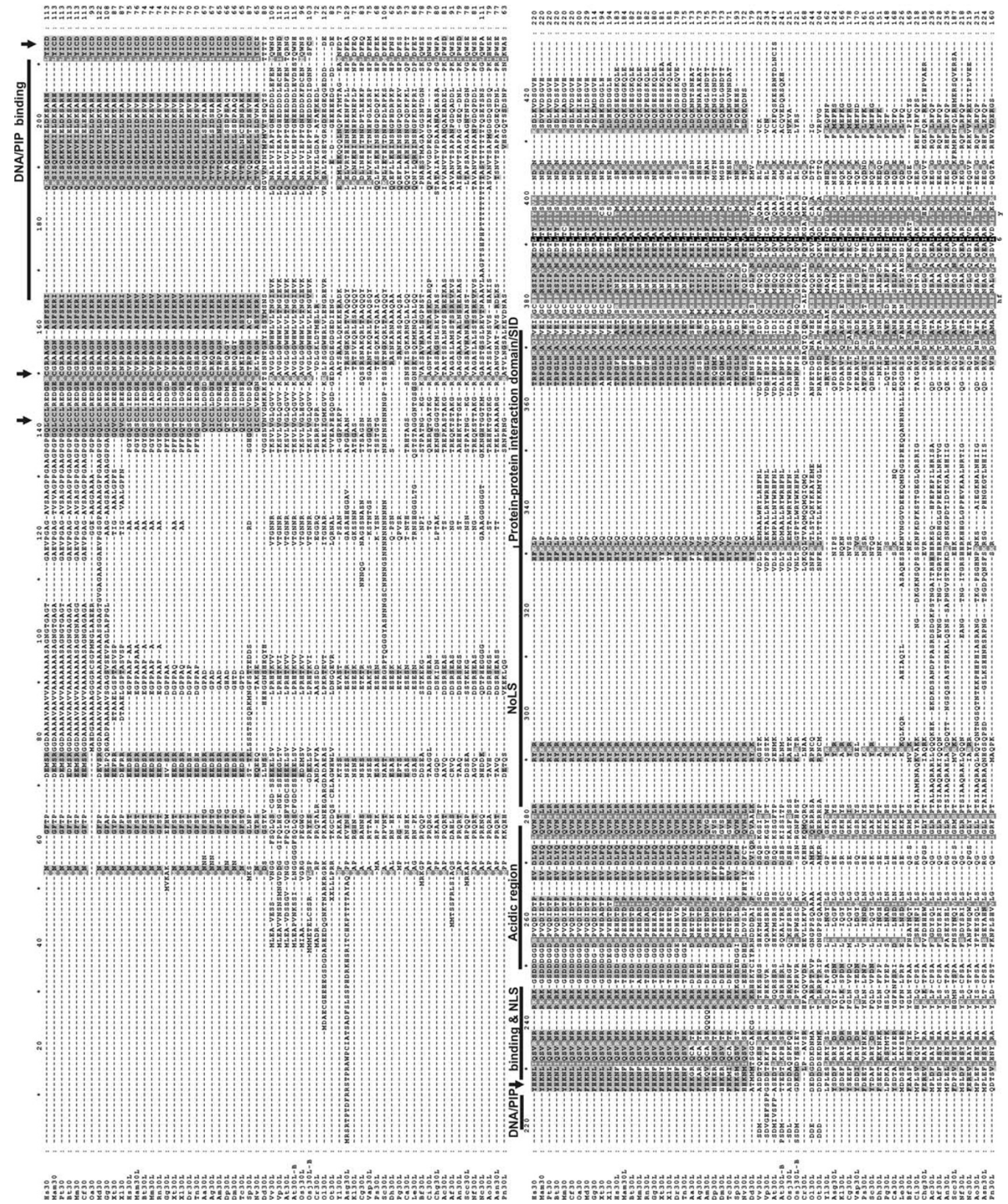

Figure 2

Amino acid sequence alignment of the members of the SAP30 family. Naming of the sequences is presented in Table I. The residues in the alignment are shaded light grey, grey, or black to indicate shared identity at $40 \%, 70 \%$ and $100 \%$, respectively. The arrows indicate the zinc coordinating residues. PIP = Phosphatidyl Inositol Phosphate, NLS = Nuclear localization signal, Acidic region = a central region contributing to histone/nucleosome binding, NoLS $=$ Nucleolar localization signal, SID = Sin3 interacting domain. 


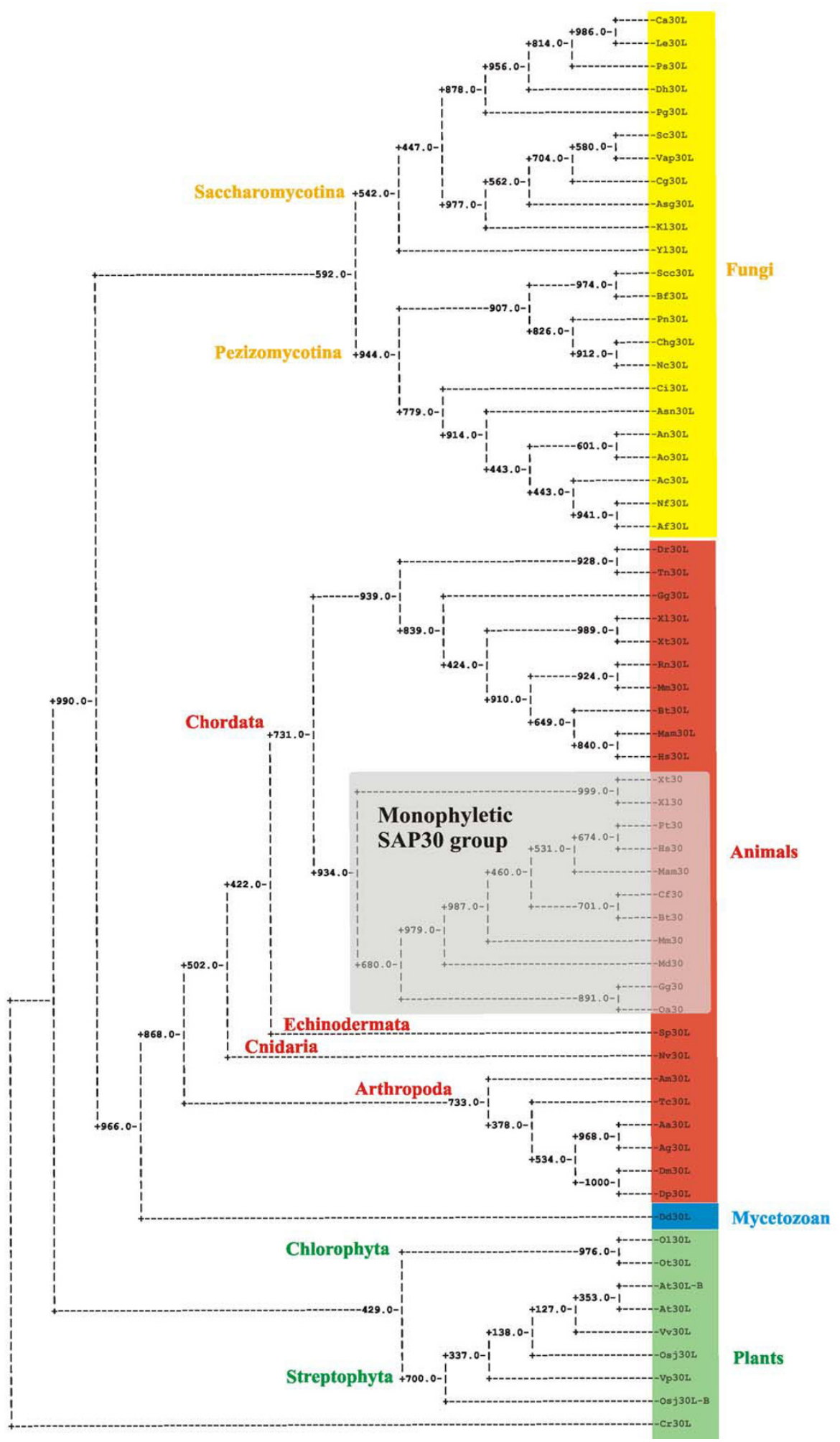

Figure 3

A phylogenetic tree of the SAP30 protein family. The tree was derived by a neighbor-joining distance analysis (the parsimony and likelihood trees are presented in Additional files 4 and 5). The statistical reliability of the inferred tree topology was assessed by the jackknife test, and the values are shown at each node as a percentage calculated from 1000 data sets. 


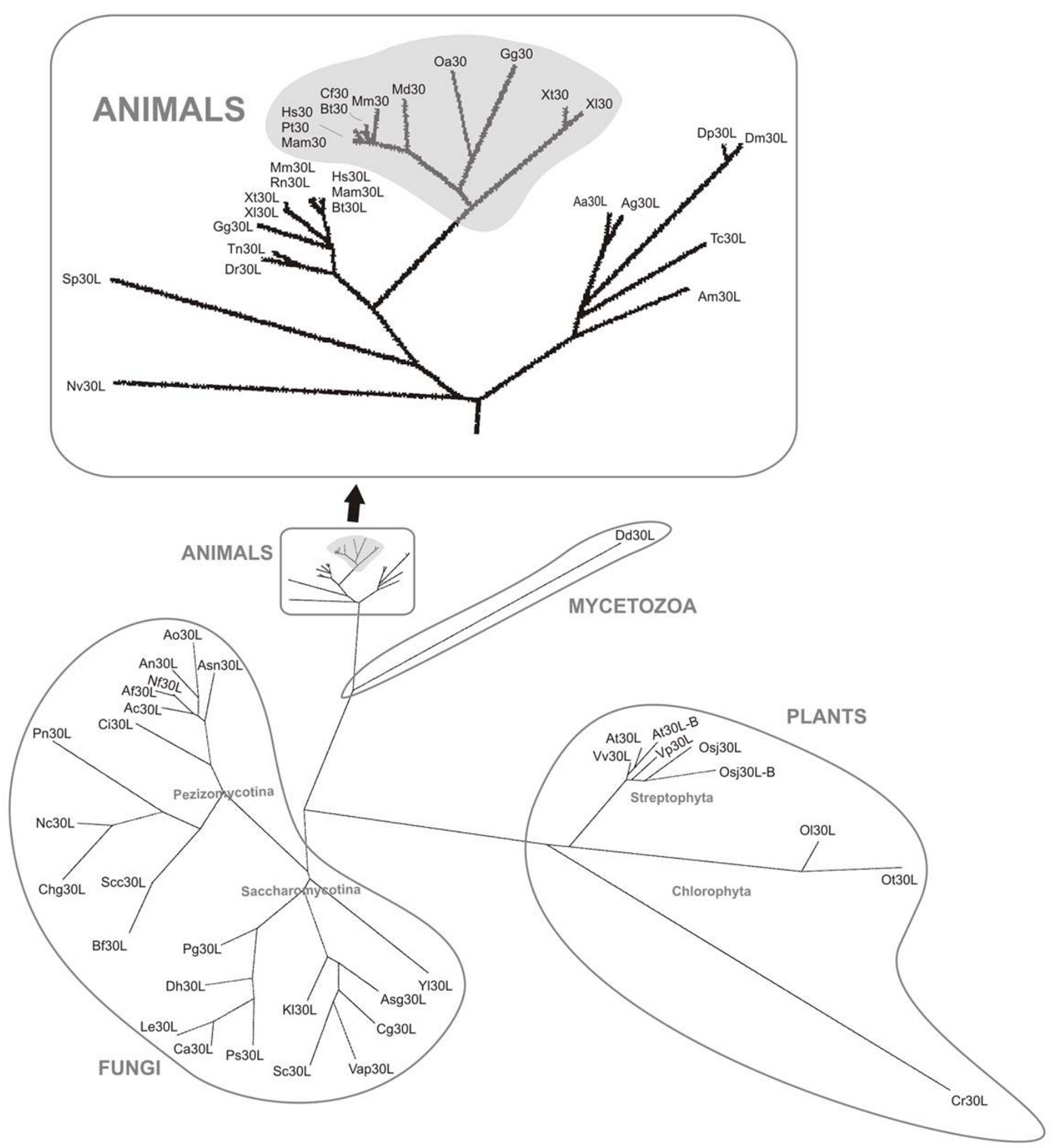

Figure 4

A phylogenetic tree of the SAP30 family in which branch lengths are proportional to the extent of sequence divergence. The black arrow points to the tip of the animal branch, which is shown magnified in the lower left corner. The dispersed, monophyletic tetrapodan/sarcopterygian SAP30 group is shaded. 
proteins contain more amino acid substitutions, and many more deletions and insertions, than the SAP30L proteins. In fact, the divergence and amino acid identity values for SAP30 protein sequences between Homo sapiens and Xenopus tropicalis are $27.2 \%$ and $74.2 \%$, respectively, whereas the corresponding values for SAP30L are $9.5 \%$ and $89 \%$. It seems that since their divergence by segmental duplication from a common ancestor, the evolutionary rate in SAP30 proteins has been much higher than in SAP30L proteins. This is what is thought to occur more generally in duplicated genes, where the new copy will evolve unencumbered by the selective constraints imposed on its progenitor [23]. Furthermore, the evolutionary rate of amino acid substitution may increase and functional divergence may take place at the early stage of evolution after separation [24]. This is followed by the late stage, in which purifying selection plays a major role in maintaining related, but distinct functions. This has allowed SAP30 to gain more length, mainly by microsatellite expansion near its N-terminus. It is not known if this has produced "gene innovation" (i.e. addition of a new functional domain) to SAP30, because the function of this $\mathrm{N}$-terminal extension is currently unknown.

Since the cluster-specific residues between SAP30 and SAP30L in the sarcopterygian clusters were prominent in the alignment, we tested whether these residues are functionally relevant. Functional significance is highly correlated with evolutionary conservation [25]. If a particular amino acid site is variable in both clusters, it is unlikely to have any major functional role in either paralog. Conversely, conservation of an amino acid in one cluster and

A
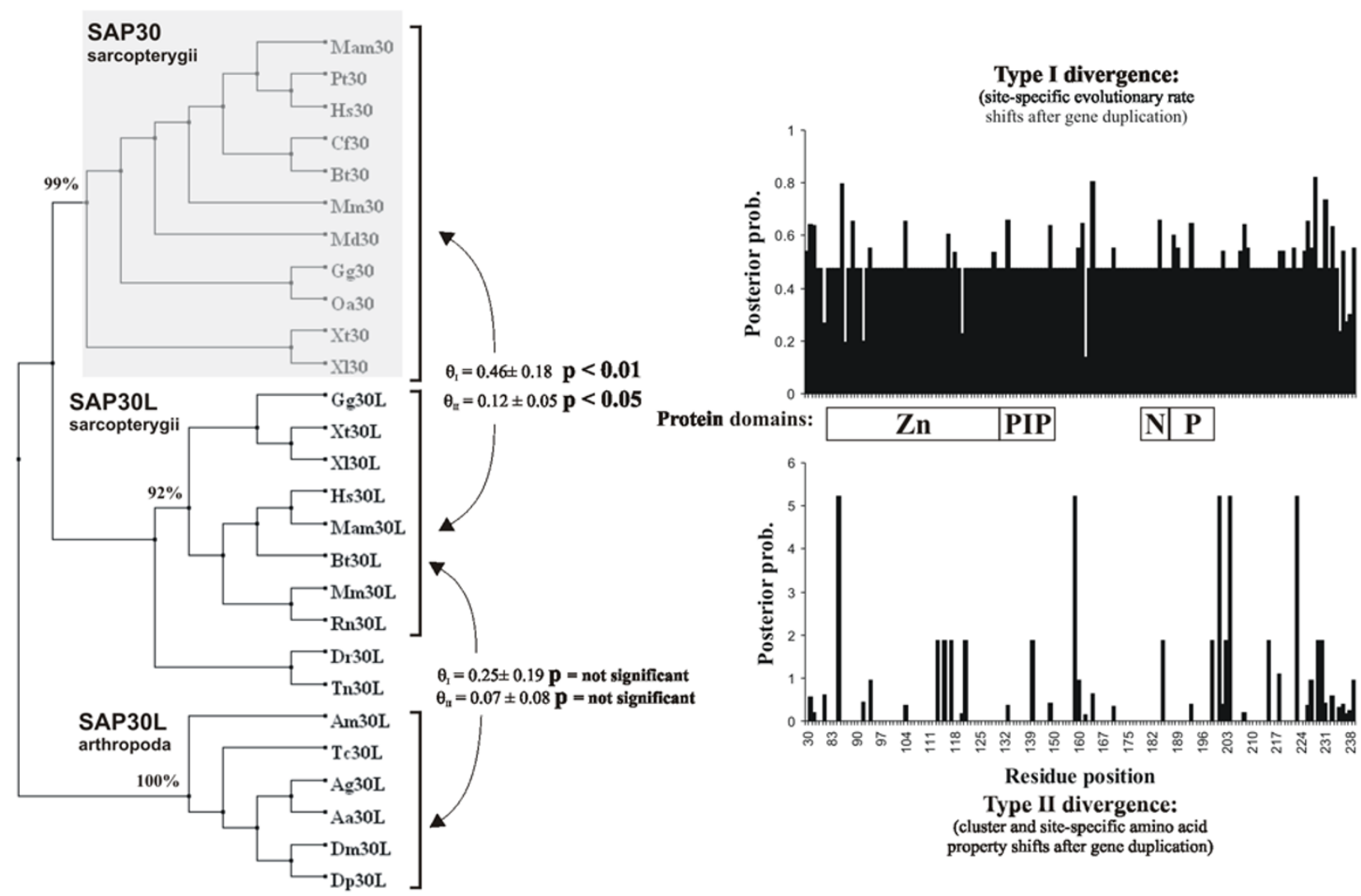

Figure 5

Functional divergence between SAP30 and SAP30L. a) A neighbor-joining tree of the tetrapodan/sarcopterygian SAP30 and SAP30L, and the arthropodan SAP30L, showing the jackknife values at the nodes. The monophyletic tetrapodan/sarcopterygian SAP30 cluster is shaded. The curved arrows indicate comparisons for type-I $\left(\theta_{\mathrm{I}}\right)$ and type-II $\left(\theta_{\| I}\right)$ functional divergence, and statistically significant $p$-values are indicated. b) Posterior probability plot of amino acid positions indicative of type-l or type-Il functional divergence. The conserved domains are depicted in the white boxes between the plots. Zn $=$ zinc dependent module, PIP = monophosphoinositide binding motif, $\mathrm{N}=$ nucleolar lozalization signal, $\mathrm{P}=$ protein-protein interaction domain. 
lack of conservation in a sister cluster is assumed to contribute to functional differences between the paralogs. This site-specific shift in the evolutionary rate between clusters is known as type-I functional divergence [26]. In type-II functional divergence, a particular site is conserved in both clusters but the physicochemical property of the amino acid is different between the clusters [27]. To test if the cluster-specific residues in SAP30 and SAP3OL are indicative of type-I divergence, we estimated the coefficient of functional divergence $(\theta)$, which measures the difference in the evolutionary rate at amino acid sites between gene clusters. Rejection of the null hypothesis $(\theta$ $=0$ ) is strong evidence for altered functional constraints after gene duplication (or speciation) [28]. We found significant evidence for type-I divergence in the comparison between sarcopterygian SAP30 and SAP30L clusters $\left(\theta_{\mathrm{I}}=\right.$ $0.46 \pm 0.18, \mathrm{p}<0.01$ Figure $5 \mathrm{a}$ ), but not in the control comparison between sarcopterygian and arthropodan SAP30L clusters $\left(\theta_{\mathrm{I}}=0.25 \pm 0.19, \mathrm{p}>0.19\right)$, which reflects the situation before the gene duplication. Similarly, significant type-II functional divergence was detected only between SAP30 and SAP30L clusters $\left(\theta_{\mathrm{II}}=0.12 \pm 0.05\right.$, p < $0.05)$, whereas it was undetectable before the gene duplication $\left(\theta_{\mathrm{II}}=0.07 \pm 0.08, \mathrm{p}>0.37\right)$. To put these findings into perspective, the human SAP30 and SAP30L share $70 \%$ amino acid identity, whereas the human SAP30L and the Drosophila melanogaster SAP30L share only 50\% identity. This latter comparison clearly shows that it is mostly the neutral amino acid sites with no functional role that are variable, whereas after the gene duplication (i.e. the emergence of SAP30), functional divergence has taken place.

To conclude, after the sarcopterygian radiation around 450 Mya, the duplicated SAP30 has diverged functionally from the ancestral SAP30L. In contrast, evolutionary constraints have kept SAP30L functionally unchanged for $\sim 1000 \mathrm{My}$, since the separation of arthropods and sarcopterygians [29]. In spite of considerable divergence in sequence, only functionally insignificant changes constitute the sequence differences in SAP30L between these two clades. This presumably reflects the fact that purifying selection has acted to conserve SAP30L.

The site-specific profile for the amino acid residues deemed responsible for type-I and type-II functional divergence (Figure 5b) show that most of the functional divergence is found in the $\mathrm{C}$-terminal region and between the experimentally identified domains. However, previous experiments have shown that: i) the repression capacity of SAP30 is only half of that of SAP30L, ii) SAP30L is able to self-oligomerize in vivo whereas SAP30 is not, and iii) SAP30L is more concentrated in the nucleolus than SAP30 in transfection experiments [8]. These biochemical data, together with the molecular evolutionary analysis described here, suggest that the original functions are executed by SAP30L, but in SAP30 these functions are abandoned or suppressed.

\section{The functional divergence between SAP3O and SAP3OL is due to differences in their association with the nuclear matrix}

Although the C-terminal region is the most conserved part in proteins of the SAP30 family, considerable type-I and type-II functional divergence has occurred in this region after the separation of the SAP30L and SAP30 genes (Figure $5 \mathrm{~b}$ ). Our previous subcellular fractionation experiments showed that nuclear retention of SAP30L is achieved by interaction with DNA through the N-terminal domain [12]. We also demonstrated that the C-terminus has a role in nuclear retention, because C-terminally truncated mutants of SAP30L leaked to the cytoplasm in transfection studies $[8,12]$. We therefore asked whether the Cterminal region constitutes a nuclear matrix association sequence. When myc-tagged constructs of wild type (wt) SAP30 and SAP30L were transfected into HeLa cells and the nuclear matrix was isolated, we noticed that staining of the perinucleolar ring was resistant to Triton-X and DNAse I treatments, indicating that the proteins remained attached to the nuclear matrix in the perinucleolar ring region (Figure 6a). SAP30L1-120 was completely soluble, while the 1-140 and 1-160 versions showed some attachment to the nuclear matrix (Figure 6a). Intriguingly, SAP30L seemed to be bound more tightly than SAP30, suggesting that SAP30 has accumulated mutations that hinder its association with the nuclear matrix. In order to gain more quantitative data, we performed subcellular fractionation experiments and found that SAP30 was considerably more soluble than SAP30L, which accumulated in the nuclear matrix/chromatin fractions. The 1-120 mutant of SAP30L showed markedly reduced accumulation in the nuclear matrix/chromatin fraction, and the 1140 and 1-160 mutants were also more soluble than wt SAP30L (Figure 6b), indicating that an intact C-terminus is necessary for the association with the nuclear matrix (see Figure 6e for a schematic representation of the domains identified in SAP30L). Since the nuclear matrix participates in gene transcription [30] and repression [31], the impaired association of the 1-140 version of SAP30L with the nuclear matrix could explain its previously observed, reduced repression activity [8].

We recently showed that the N-terminal zinc-dependent module and the following hydrophobic region together with polybasic region/NLS are needed for DNA binding in vitro and chromatin association in vivo [12]. As shown in Figure 6c (left panel), solubilization of chromatin with micrococcal nuclease does not detach wt SAP30 or wt SAP30L from the nuclear matrix. Their attachment is dependent on an intact C-terminus, which thus consti- 

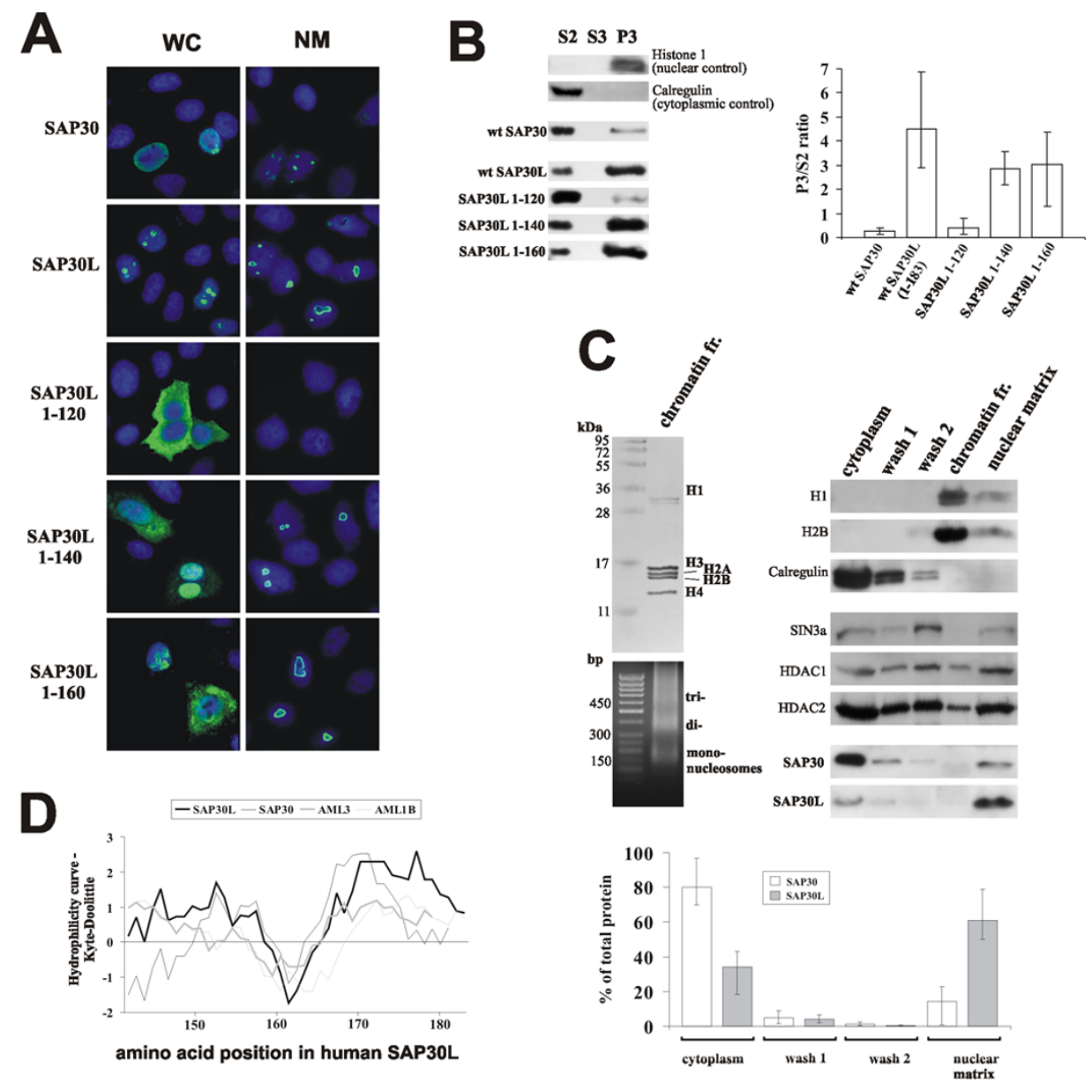

E

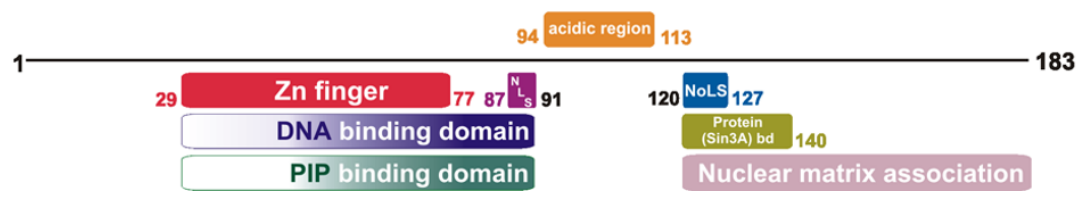

Figure 6

A nuclear matrix association sequence consists of the nucleolar localization signal and the conserved $\mathrm{C}$-terminus. a) Hela cells were transfected with the indicated, myc-tagged constructs and the nuclear matrix was prepared. NM, nuclear matrix preparation; WC, whole cell. Subsequently the cells were stained with an antibody against the myc tag, mounted in DAPI and photographed on a confocal microscope. b) HEK293T cells were transfected with the indicated constructs, fractionated into subcellular fractions, and immunoblotted with the antibodies as indicated. S2, S3 and P3 correspond to the cytoplasmic soluble, nuclear soluble and nuclear insoluble (chromatin and nuclear matrix) fractions, respectively. The data from three independent experiments are illustrated as histograms in which the bars represent the range of band intensities measured with a densitometer. c) HEK293T cells were transfected with myc-tagged SAP30 and SAP30L proteins, and nucleosomes were isolated. In the left upper panel, a Coomassie-stained gel shows release of histones, and an agarose gel (left lower panel) shows the accompanying release of nucleosomal DNA from the nucleus after treatment with micrococcal nuclease. The proteins from each step of nucleosome isolation were analysed on the immunoblot shown in the right panel. The data from the three independent experiments are illustrated in the histograms, as in (b). d) A Kyte-Doolittle Hydrophilicity plot of the nuclear matrix association sequences from proteins of the SAP30 and AML [43] families. e) A schematic representation of the domains identified in SAP30L. NLS, nuclear localization signal; NoLS, nucleolar localization signal; Protein bd, the protein-binding domain and nuclear matrix association sequence identified in this study. The numbers indicate amino acid positions. The color gradients depict more strongly interacting regions in darker colors. The zinc finger is necessary for proper presentation of these regions to DNA or phosphoinositides. 
tutes a nuclear matrix association sequence (Figure 6c, right panel). The association of SAP30 with the nuclear matrix seems to be weaker than that of SAP30L. Alternatively, SAP30 may possess a less effective NLS or NoLS and/or a more effective nuclear export signal (NES). Interestingly, Sin3A has also been reported to associate with the nuclear matrix [32], and we used it as a control nuclear matrix protein. Taken together, these findings show that proteins of the SAP30 family are able to interact with corepressors (e.g. Sin3, N-CoR), associate with the nuclear matrix, and bind DNA, and therefore possess many characteristics typical of nuclear scaffolding proteins [33]. A well studied example of nuclear scaffolding proteins is provided by members of the RUNX family of transcription factors, which are tissue-specific regulatory proteins involved in the control of hematopoiesis (Runx1/AML1), osteogenesis (Runx2/AML3), and differentiation of neural and gastrointestinal cells (Runx3/AML2) [34]. Their N-terminal parts bind specific DNA sequences, whereas the Cterminal domains interact with coregulatory factors and associate with the nuclear matrix [34], a domain organization similar to that in proteins of the SAP30 family. In addition, the subcellular localization of proteins of the two families also bears similarities, as Runx proteins are focally localized within the nucleus and some of them are actually found in the nucleolus [35]. Interestingly, the nuclear matrix association sequence in both protein families is comprised of a stretch of hydrophobic residues flanked by hydrophilic residues (Figure 6d).

It is now widely accepted that in higher organisms such as mammals, a particular function is often assigned to a gene family rather than to a single gene. Many gene families are thought to have originated by gene duplication at an evolutionary stage when most vertebrates were still aquatic [36]. The members of a gene family perform the same or similar function, but in slightly different and overlapping ways. In the case of the SAP30 family, these subtle differences may be exploited during ontogeny, given the crucial role reserved for the Sin3A complex in embryogenesis [1].

\section{Conclusion}

In this report, we have described the molecular evolution of the SAP30 protein family and its genesis from a single chromosome segment duplication event. Our analyses indicate that the ancestral SAP30L protein is conserved in animals, plants, fungi and some chloroplast-containing protists. We have identified many new members of the SAP30 family from different species and a conserved Cterminal domain which is responsible for association with the nuclear matrix. The phylogenetic and biochemical analyses have uncovered functional divergence between SAP30 and SAP30L in the domain that associates with the nuclear matrix. These data will facilitate further studies on the functional role of proteins of the SAP30 family in the
Sin3-HDAC corepressor complex, and possibly other complexes as well.

\section{Methods \\ Protein sequence searches, gene locus data retrieval and multiple sequence alignments}

Protein Psi-Blast [37] searches with the full length human SAP30L sequence were performed at the NCBI Web site http://www.ncbi.nlm.nih.gov/BLAST/ on the non-redundant protein sequence database available on December 3, 2007. After six rounds of iteration, SAP30 and SAP30L orthologs below an E-value of 0.005 (except for Phaeosphaeria nodorum, for which the E-value was 0.011) were selected from metazoa, plants and fungi, and all redundant sequences were excluded. SAP30 and SAP30L proteins are encoded in four exons, and variable usage of these exons is reported to yield multiple splicing variants [38]. It is also predicted that the longer SAP30 and SAP30L cDNAs are composed of additional spliced-in, upstream exons. These predicted additional exons (Rattus norvegicus SAP30L, gi|109490760) were excluded from our analyses, all of which were done on protein sequences that contained the four complete exons, for the sake of clarity. All sequences were collected in FASTA format for further analysis as shown in Table 1. The identification and naming of the protein sequences as either SAP30 or SAP30L is based on the phylogenetic analyses shown in Figures 3 and 4 . The SAP30 and SAP30L sequences were aligned using the MegAlign $5.06^{\circ}$ program (DNASTAR Inc) with Clustal $\mathrm{V}$ [39] or $\mathrm{W}[40]$ at default settings. The alignments were then shaded using the multiple sequence alignment editor GENEDOC http://www.nrbsc.org/gfx/ genedoc/index.html. Gene locus data were retrieved from the NCBI Map viewer http://www.ncbi.nlm.nih.gov/ mapview/.

\section{Phylogenetic analysis and detection of functional divergence}

PHYLIP version 3.67 [41] was used for the phylogenetic analyses. Distance, parsimony and likelihood analyses were performed using the protein alignment as input. Jackknife values were obtained using SEQBOOT and creating 1000 or 100 "delete-half jackknife" data sets. The distance analysis was performed by using PROTDIST and subsequently NEIGHBOR with standard parameters, and the parsimony analysis was performed using PROTPARS with standard parameters. The Likelihood analysis was performed by using PROML with standard parameters. In all cases, the " $\mathrm{M}$ " option for the analysis of multiple data sets created with SEQBOOT was invoked.

We used DIVERGE version 2.0 [42] for detecting type-I [26] and type-II [27] functional divergence. Clustal W alignments of the arthropodan and sarcopterygian clades for SAP30L and the sarcopterygian clade for SAP30 were 
created, and a distance analysis with 100 "delete-half jackknife" data set tests was performed using PHYLIP as described above. It should be noted that we used tetrapod sequences as representatives of the sarcopterygian clade due to the lack of sequence data from the Dipnoi (lungfish) and Coelacanthimorpha infra- and subclasses. The alignment and the neighborjoining tree were used as input for the functional divergence analyses. P-values were derived from the $\theta$ and standard error values using the Z-score.

\section{Cell culture and transfections}

Human embryonic kidney epithelial cells (HEK293T) were cultured in DMEM (Gibco) containing 5\% fetal bovine serum, $1 \mathrm{mM}$ sodium pyruvate, $50 \mu \mathrm{g} / \mathrm{ml}$ uridine, penicillin and streptomycin. HeLa cells were cultured in RPMI1640 (Gibco) supplemented with 10\% fetal bovine serum, L-glutamine, penicillin and streptomycin. DNA was transfected using FuGENE 6 (for HEK293T cells) or FuGENE HD (for HeLa cells) reagents (Roche) according to the manufacturer's protocol.

\section{Preparation and staining of the nuclear matrix}

Nuclear matrix preparations were done as described [43]. Subsequently the cells were fixed and stained as described previously [8].

\section{Preparation of the chromatin-enriched fraction and nucleosomes}

Isolation of chromatin and the nuclear matrix, and subcellular fractionation were performed as described previously [44]. Nucleosomes were prepared as described in [45].

\section{Authors' contributions}

KMV designed the study, carried out the phylogenetic analyses, performed the laboratory work and wrote the manuscript. TYKH was involved in the conception of the study, and participated in the interpretation of the data and writing of the manuscript. MM participated in the coordination of the project and helped to draft the manuscript. OL contributed to the conception and design of the study and helped to write the manuscript. All authors have read and approved the final manuscript.

\section{Additional material}

\section{Additional file 1}

Clustal $V$ alignment of the SAP30 family members in plants.

Click here for file

[http://www.biomedcentral.com/content/supplementary/14712148-9-149-S1.pdf]

\section{Additional file 2}

Clustal V alignment of the SAP3O family members in animals. The arrows indicate the zinc coordinating residues. Red arrows and green boxes indicate the locations of secondary structural elements as deduced from the solution structure [13].

Click here for file

[http://www.biomedcentral.com/content/supplementary/14712148-9-149-S2.pdf]

\section{Additional file 3}

Clustal $W$ alignment of the SAP3O family members in yeasts. Click here for file

[http://www.biomedcentral.com/content/supplementary/14712148-9-149-S3.pdf]

\section{Additional file 4}

Maximum parsimony phylogenetic tree of the SAP30 protein family. The statistical reliability of the inferred tree topologies was assessed by the jackknife test. The jackknife values from 1000 data sets are shown at each node. The monophyletic tetrapodan/sarcopterygian SAP30 group is shaded.

Click here for file

[http://www.biomedcentral.com/content/supplementary/14712148-9-149-S4.pdf]

\section{Additional file 5}

Maximum likelihood phylogenetic tree of the SAP30 protein family. The statistical reliability of the inferred tree topologies was assessed by the jackknife test. The jackknife values from 100 data sets are shown at each node. The monophyletic tetrapodan/sarcopterygian SAP30 group is shaded.

Click here for file

[http://www.biomedcentral.com/content/supplementary/14712148-9-149-S5.pdf]

\section{Acknowledgements}

We thank Jorma Kulmala for technical assistance and Dr Laura Kvist (Oulu, Finland) for advice. This work was supported by the Academy of Finland Research Council for Health (funding decision numbers II 5260 and 20136I), the Foundation for Paediatric Research in Finland, the Competitive Research Funding of the Pirkanmaa Hospital District (EVO), the Nona and Kullervo Väre Foundation, and the Päivikki and Sakari Sohlberg Foundation

\section{References}

I. Cowley SM, Iritani BM, Mendrysa SM, Xu T, Cheng PF, Yada J, Liggitt $H D$, Eisenman RN: The mSin3A chromatin-modifying complex is essential for embryogenesis and T-cell development. Mol Cell Biol 2005, 25:6990-7004.

2. Zhang Y, Iratni R, Erdjument-Bromage H, Tempst P, Reinberg D: Histone deacetylases and SAP I 8, a novel polypeptide, are components of a human Sin3 complex. Cell 1997, 89:357-364.

3. Zhang Y, Sun ZW, Iratni R, Erdjument-Bromage H, Tempst P, Hampsey M, Reinberg D: SAP30, a novel protein conserved between human and yeast, is a component of a histone deacetylase complex. Mol Cell 1998, I:I02I-I031.

4. Laherty CD, Billin AN, Lavinsky RM, Yochum GS, Bush AC, Sun JM, Mullen TM, Davie JR, Rose DW, Glass CK, et al.: SAP30, a component of the $\mathrm{mSin} 3$ corepressor complex involved in N-CoR- 
mediated repression by specific transcription factors. Mol Cell 1998, 2:33-42.

5. Hsieh JJ, Zhou S, Chen L, Young DB, Hayward SD: CIR, a corepressor linking the DNA binding factor CBFI to the histone deacetylase complex. Proc Natl Acad Sci USA 1999, 96:23-28.

6. Huang NE, Lin CH, Lin YS, Yu WC: Modulation of YYI activity by SAP30. Biochem Biophys Res Commun 2003, 306:267-275.

7. Lindfors K, Viiri KM, Niittynen M, Heinonen TY, Maki M, Kainulainen $\mathrm{H}$ : TGF-beta induces the expression of SAP30L, a novel nuclear protein. BMC Genomics 2003, 4:53.

8. Viiri KM, Korkeamaki $H$, Kukkonen MK, Nieminen LK, Lindfors $K$, Peterson P, Maki M, Kainulainen H, Lohi O: SAP30L interacts with members of the Sin $3 A$ corepressor complex and targets Sin3A to the nucleolus. Nucleic Acids Res 2006, 34:3288-3298.

9. Sun ZW, Hampsey M: A general requirement for the Sin3-Rpd3 histone deacetylase complex in regulating silencing in Saccharomyces cerevisiae. Genetics 1999, 152:921-932.

10. Smith JS, Caputo E, Boeke JD: A genetic screen for ribosomal DNA silencing defects identifies multiple DNA replication and chromatin-modulating factors. Mol Cell Biol 1999, 19:3184-3197.

II. Meskauskas A, Baxter JL, Carr EA, Yasenchak J, Gallagher JE, Baserga S), Dinman JD: Delayed rRNA processing results in significant ribosome biogenesis and functional defects. Mol Cell Biol 2003, 23:1602-1613.

12. Viiri KM, Janis J, Siggers T, Heinonen TY, Valjakka J, Bulyk ML, Maki M, Lohi O: DNA-binding and -bending activities of SAP3OL and SAP30 are mediated by a zinc-dependent module and monophosphoinositides. Mol Cell Biol 2009, 29:342-356.

13. He $Y$, Imhoff $R$, Sahu A, Radhakrishnan I: Solution structure of a novel zinc finger motif in the SAP30 polypeptide of the Sin 3 corepressor complex and its potential role in nucleic acid recognition. Nucleic Acids Res 2009, 37:2 142-2I 52.

14. Friedman R, Hughes AL: The temporal distribution of gene duplication events in a set of highly conserved human gene families. Mol Biol Evol 2003, 20:154-161.

15. Schmutz J, Martin J, Terry A, Couronne O, Grimwood J, Lowry S, Gordon LA, Scott D, Xie G, Huang W, et al: The DNA sequence and comparative analysis of human chromosome 5. Nature 2004, $431: 268-274$.

16. Kumar S, Hedges SB: A molecular timescale for vertebrate evolution. Nature 1998, 392:917-920.

17. Woods IG, Kelly PD, Chu F, Ngo-Hazelett P, Yan YL, Huang H, Postlethwait JH, Talbot WS: A comparative map of the zebrafish genome. Genome Res 2000, 10:1903-19|4.

18. Liu TX, Zhou Y, Kanki JP, Deng M, Rhodes J, Yang HW, Sheng XM, Zon LI, Look AT: Evolutionary conservation of zebrafish linkage group 14 with frequently deleted regions of human chromosome 5 in myeloid malignancies. Proc Natl Acad Sci USA 2002, 99:6|36-6|4|.

19. Karolchik D, Kuhn RM, Baertsch R, Barber GP, Clawson H, Diekhans M, Giardine B, Harte RA, Hinrichs AS, Hsu F, et al:: The UCSC Genome Browser Database: 2008 update. Nucleic Acids Res 2008, 36:D773-779.

20. Ekwall K: Genome-wide analysis of HDAC function. Trends Genet 2005, 21:608-6I5.

21. James TY, Kauff F, Schoch CL, Matheny PB, Hofstetter V, Cox CJ, Celio G, Gueidan C, Fraker E, Miadlikowska J, et al.: Reconstructing the early evolution of Fungi using a six-gene phylogeny. Nature 2006, 443:818-822.

22. Hedges SB: The origin and evolution of model organisms. Nat Rev Genet 2002, 3:838-849.

23. Ohno S: Evolution by Gene Duplication Berlin: Springer-Verlag; 1970.

24. Li WH: Evolution of duplicated genes. In Evolution of genes and proteins Koehn MNaRK: Sinauer, Sunderland, Mass; 1983:14-37.

25. Kimura M: The Neutral Theory of Molecular Evolution Cambridge: Cambridge University Press; 1983.

26. Gu X: Statistical methods for testing functional divergence after gene duplication. Mol Biol Evol 1999, 16:1664-1674.

27. Gu X: A simple statistical method for estimating type-II (cluster-specific) functional divergence of protein sequences. Mol Biol Evol 2006, 23: 1937-1945.

28. Gu X: Functional divergence in protein (family) sequence evolution. Genetica 2003, I I 8:133-141.
29. Wang DY, Kumar S, Hedges SB: Divergence time estimates for the early history of animal phyla and the origin of plants, animals and fungi. Proc Biol Sci 1999, 266:163-171.

30. Mika S, Rost B: NMPdb: Database of Nuclear Matrix Proteins. Nucleic Acids Res 2005, 33:DI60-163.

3I. Rampalli S, Pavithra L, Bhatt A, Kundu TK, Chattopadhyay S: Tumor suppressor SMAR I mediates cyclin DI repression by recruitment of the SIN3/histone deacetylase I complex. Mol Cell Biol 2005, 25:84I5-8429.

32. Imai Y, Kurokawa M, Yamaguchi Y, Izutsu K, Nitta E, Mitani K, Satake $M$, Noda $T$, Ito $Y$, Hirai $H$ : The corepressor $m$ Sin $3 A$ regulates phosphorylation-induced activation, intranuclear location, and stability of AMLI. Mol Cell Biol 2004, 24: I033-1043.

33. Zaidi SK, Young DW, Javed A, Pratap J, Montecino M, van Wijnen A, Lian JB, Stein JL, Stein GS: Nuclear microenvironments in biological control and cancer. Nat Rev Cancer 2007, 7:454-463.

34. Javed A, Barnes GL, Pratap J, Antkowiak T, Gerstenfeld LC, van Wijnen AJ, Stein JL, Lian JB, Stein GS: Impaired intranuclear trafficking of Runx2 (AML3/CBFAI) transcription factors in breast cancer cells inhibits osteolysis in vivo. Proc Natl Acad Sci USA 2005, 102:1454-1459.

35. Young DW, Hassan MQ, Pratap J, Galindo M, Zaidi SK, Lee SH, Yang $X$, Xie R, Javed A, Underwood JM, et al:: Mitotic occupancy and lineage-specific transcriptional control of rRNA genes by Runx2. Nature 2007, 445:442-446.

36. Ohno S, Wolf U, Atkin NB: Evolution from fish to mammals by gene duplication. Hereditas 1968, 59:169-187.

37. Altschul SF, Madden TL, Schaffer AA, Zhang J, Zhang Z, Miller W, Lipman DJ: Gapped BLAST and PSI-BLAST: a new generation of protein database search programs. Nucleic Acids Res 1997, 25:3389-3402.

38. Korkeamaki H, Viiri K, Kukkonen MK, Maki M, Lohi O: Alternative mRNA splicing of SAP3OL regulates its transcriptional repression activity. FEBS Lett 2008, 582:379-384.

39. Higgins DG, Sharp PM: Fast and sensitive multiple sequence alignments on a microcomputer. Comput Appl Biosci 1989 , 5:|15I-I53.

40. Thompson JD, Higgins DG, Gibson TJ: CLUSTAL W: improving the sensitivity of progressive multiple sequence alignment through sequence weighting, position-specific gap penalties and weight matrix choice. Nucleic Acids Res 1994, 22:4673-4680.

4I. Felsenstein J: PHYLIP (phylogeny inference package). Version 3.2. Cladistics 1989, 5:164-166.

42. Gu X, Velden K Vander: DIVERGE: phylogeny-based analysis for functional-structural divergence of a protein family. Bioinformatics 2002, 18:500-50I.

43. Zeng C, van Wijnen AJ, Stein JL, Meyers S, Sun W, Shopland L, Lawrence JB, Penman S, Lian JB, Stein GS, Hiebert SW: Identification of a nuclear matrix targeting signal in the leukemia and bonerelated AML/CBF-alpha transcription factors. Proc Natl Acad Sci USA 1997, 94:6746-675।.

44. Mendez J, Stillman B: Chromatin association of human origin recognition complex, cdc6, and minichromosome maintenance proteins during the cell cycle: assembly of prereplication complexes in late mitosis. Mol Cell Biol 2000, 20:8602-86I2.

45. Macfarlan T, Kutney S, Altman B, Montross R, Yu J, Chakravarti D: Human THAP7 is a chromatin-associated, histone tail-binding protein that represses transcription via recruitment of HDAC3 and nuclear hormone receptor corepressor. I Biol Chem 2005, 280:7346-7358. 